\title{
AIRCRAFT CLOUDS
}

\section{FROM CHEMTRAIL PSEUDOSCIENCE TO THE SCIENCE OF CONTRAILS}

Jordi Mazon, Marcel Costa and David Pino

The most frequent statements and arguments found in pseudoscience websites and forums supporting the existence of so-called aircraft chemtrails can be refuted with a scientific explanation of the processes resulting in the formation of condensation or deposition trails, known as contrails. Thus, the hypothesis that chemtrails exist is disproven by the scientific literature that shows that they are the exact same entity as contrails: They are hydrological phenomena which result from a physical process referenced in the many studies carried out since the beginning of the age of aviation, in the early twentieth century. Hence, in this paper we conclude that pseudoscience's chemtrails are nothing more than the contrails described by science.

Keywords: chemtrails, contrails, pseudoscience, science, high-level clouds.

Rarely does pseudoscience address the formation of aircraft trails in the sky. These trails are usually discussed by conspiracy theorists, rather than by pseudoscience. Conspiracy theorists call chemtrails (chemical trails) the trails sometimes left in the sky by aircraft. According to these theories, they are the result of secret, usually governmental, projects which only an elite minority know about, with the aim of spraying chemicals from a height for different reasons such as controlling the population or climate or interfering with communications. Other groups argue that, indeed, aircraft trails are not the result of dumped chemicals, but contrails (condensation trails) are produced with the objective of modifying or controlling the climate.

The scientific community has sometimes publicly noted the lack of science-based evidence regarding chemtrail theories. In 2000, several scientific organisations, NASA and NOAA (National Oceanic and Atmospheric Administration) among them, had already published a document to refute such chemtrail conspiracy theories.' More recently, worldwide

\footnotetext{
${ }^{1}$ https://www.faa.gov/regulations_policies/policy_guidance/envir_ policy/media/contrails.pdf
}

surveys carried out by Mercer, Keith, and Sharp (2011) showed that $14 \%$ of those polled partially believed in conspiracy theories related to chemtrails, and almost $3 \%$ were convinced.

Shearer, West, Caldeira, and Davis (2016) determined that, at the international level, almost $17 \%$ of the population believe in global-scale secret projects associated with chemtrails or geoengineering. The number of websites devoted to the topic has multiplied in recent years, as has as the number of papers and discussion forums devoted to it. These authors also asked a group of prestigious atmospheric physicists for their opinion. Of the 77 interviewees, 76 stated there was no evidence of conspiracy plots or for the existence of chemtrails. Of the scientists most experienced in the field, $99 \%$ stated that chemtrails are the visible part of the water vapour exhaust expelled by aircraft turbines after combustion, the result of water steam to form ice crystals.

\section{ARGUMENTS AND COUNTERARGUMENTS}

The objective of this paper is to present the main arguments made in group forums and found on the Internet in support of the existence of chemtrails, and to refute them with scientific counterarguments that 
allow us to deny their existence. Chemtrail-supporting websites have not been referenced because they are not scientific publications.

\section{Argument 1: Aircraft did not previously leave trails, the phenomenon started a few years ago}

Schumann (1996) determined that the first reference to the observation of aircraft trails dates back to 1919 . Between 1914 and 1919, aircraft started reaching the medium and upper layers of the troposphere. Ettenreich (1919) described the 1915 observation in the South Tyrol thus: «the condensation of a cumulus stripe from the exhaust gases of an aircraft was visible for a while in the sky». Weickmann (1919) described the observation of a stripe extending approximately 50 kilometres, forming structures that he attributed to groups of vortices. Parts of a $22^{\circ}$ halo were observed around the solar disk in the area of the trail, implying that it must have been formed by ice crystals with a hexagonal prism shape. Henceforth many other authors also referred to similar observations. Varney (1921) first considered the possibility that, unlike liquid water, water vapour emitted following avionic fuel combustion could oversaturate the air and lead to the formation of clouds. The emission of dust and fine particles from the aircraft turbine, which would provide condensation nuclei upon which water vapour would desublimate, was proposed by the aforementioned authors as a mechanism to explain oversaturation with respect to the ice.

During World War II, air traffic intensified, and trail observations accordingly increased. Ryan, MacKenzie, Watkins, and Timmis (2011) used historical photographs to analyse the trails of war planes and compared their expansion and evolution in the sky with those of current trails, but observed no variation. These authors examined pictures of aircraft from between 1943 and 1945 , in which bombers left a trail while other aircraft flying at lower altitudes did not.

\section{"THE SCIENTIFIC COMMUNITY HAS SOMETIMES PUBLICLY NOTED THE LACK OF SCIENCE-BASED EVIDENCE REGARDING CHEMTRAIL THEORIES"}

on the proportion of water vapour and heat of the gases released into the atmosphere by the turbine. He also developed a graphic system that allows to determine whether an aircraft in a given situation can form contrails or not.

Contrails, like naturally formed high-level clouds, play an important role in the energy balance of the Earth. High-level research and knowledge about trail thermodynamics leaped forward thanks to several authors. The term condensation trail was defined by Brewer (1946), and several years later Appleman (1953) used the portmanteau contrail. Appleman also developed the currently accepted theory regarding the formation of contrails: the temperature necessary for air saturation depends on the pressure, temperature, and humidity of the air expelled from the turbine, as well as clouds, formed by ice crystals in the upper troposphere, cover approximately 20-30\% of the Earth's surface (Schröder et al., 2000). However, the increase in air traffic in recent decades, and the consequent increase in contrails, are contributing an additional $0.5 \%$ global cover of ice crystals per decade, thus modifying the energy balance of the Earth by around $0.2-0.3^{\circ} \mathrm{C}$ per decade (Minnis, Ayers, Palikonda, \& Phan, 2004). 

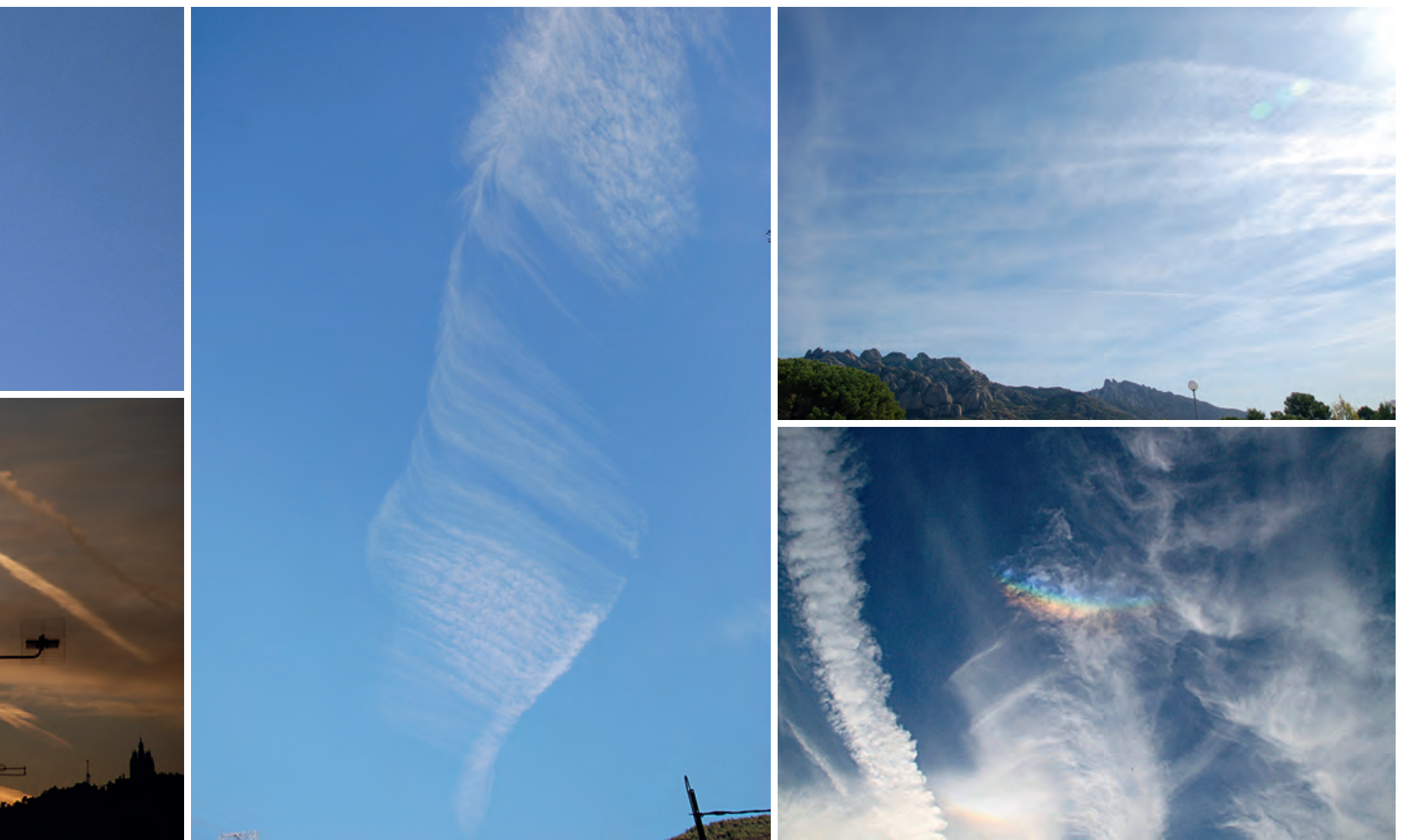

Figure 2. Examples of the three types of high-level anthropic clouds. In the left picture, detail of an aircraft contrail forming an anthropoCirrus in the "fibrous» section in the centre of the picture, and an anthropoCirrocumulus in the "grainy" structures in the upper and lower sections (Sant Pere de Torelló, Barcelona, November 2012). The top right picture shows an anthropoCirrostratus, formed from the dispersion of ice crystals from many contrails, in the areas where the sky has a uniformly white colour, as in a large section of the bottom right third of the picture (El Bruc, Barcelona, September 2015). The bottom right picture shows an anthropoCirrocumulus and anthropoCirrostratus refracting sunlight which gives them the «rainbow» colours shown in the image (Viladecans, Barcelona, December 2015).

\section{Argument 2: Chemtrails cannot be contrails because their occurrence is not regular}

Aircraft propulsion is based on kerosene combustion which expels air backwards while pushing the aircraft forward. This reaction produces water vapour and carbon dioxide (common to all combustion processes), as well as aerosols (solid microscopic particles), produced by incomplete combustion or due to impurities. These aerosols, as well as others already present in the air, act as nuclei upon which water vapour can condense or desublimate, depending on the air temperature. While cruising, commercial aircraft fly at heights over 6,000 metres, at which the air temperature is always below zero. At these altitudes, water vapour desublimates and forms ice crystals, which crystallise in a hexagonal shape to form small tiles and needles.

Once the ice crystal or water droplet is formed (often in a suffusion state), its permanence in the atmosphere depends, basically, on the temperature and humidity conditions of the air. For a contrail to be formed, air needs to be below $-40^{\circ} \mathrm{C}$ (Schumann \& Wendling, 1990). If the air temperature is higher, the ice crystal will tend to sublimate; the hotter the air, the faster it will sublimate. Similarly, the drier the air, the faster the sublimation of the crystal or the water evaporation. In a relatively humid environment, both the droplet and the ice crystal can survive for longer: several hours or even more than a day. Schumann and Wendling (1990) argue that contrails require a special thermodynamic state, with air temperature lower than $230 \mathrm{~K}\left(-43^{\circ} \mathrm{C}\right)$ and a pressure nearing $250 \mathrm{hPa}$ (at heights around 9,500 metres).

According to Kärcher, Peter, Biermann, and Schumann (1996), contrail crystals sublimate within the first few seconds of their formation process if the air is dry. For the ice crystals in a contrail to persist, Gierens (1996) determined that the air must have a 
relative humidity of at least $70 \%$ with respect to the ice. Furthermore, at this relative humidity level, the growth rate of the contrail crystals increases as temperature decreases. Figure 1 shows an example of the structure of contrails formed under different atmospheric conditions.

So, temperature and humidity condition the appearance of contrail ice crystals, and these can develop and spread in environments that are saturated relative to the ice, causing them to transform into high-level clouds that can adopt the structure of cirrus, cirrostratus, or cirrocumulus (Minnis et al., 1998). Mazon, Costa, Pino, and Lorente (2012) propose calling the clouds formed by human activity anthropoclouds, introducing the prefix anthropo- to differentiate them from clouds whose origin is natural. Thus, the anthropoclouds formed from aircraft trails, usually called contrails, would be high-level anthropoclouds. The three basic types of highlevel clouds would be called anthropoCirrus (aCi), anthropoCirrostratus (aCs), and anthropoCirrocumulus $(\mathrm{aCc})$, when they originate from contrails. Figure 2 shows several types of high-level anthropic clouds formed from condensation trails.

Consequently, the fact that on some days more examples of aircraft trails are visible depends only on the air temperature and humidity conditions at the altitude at which the planes are flying.

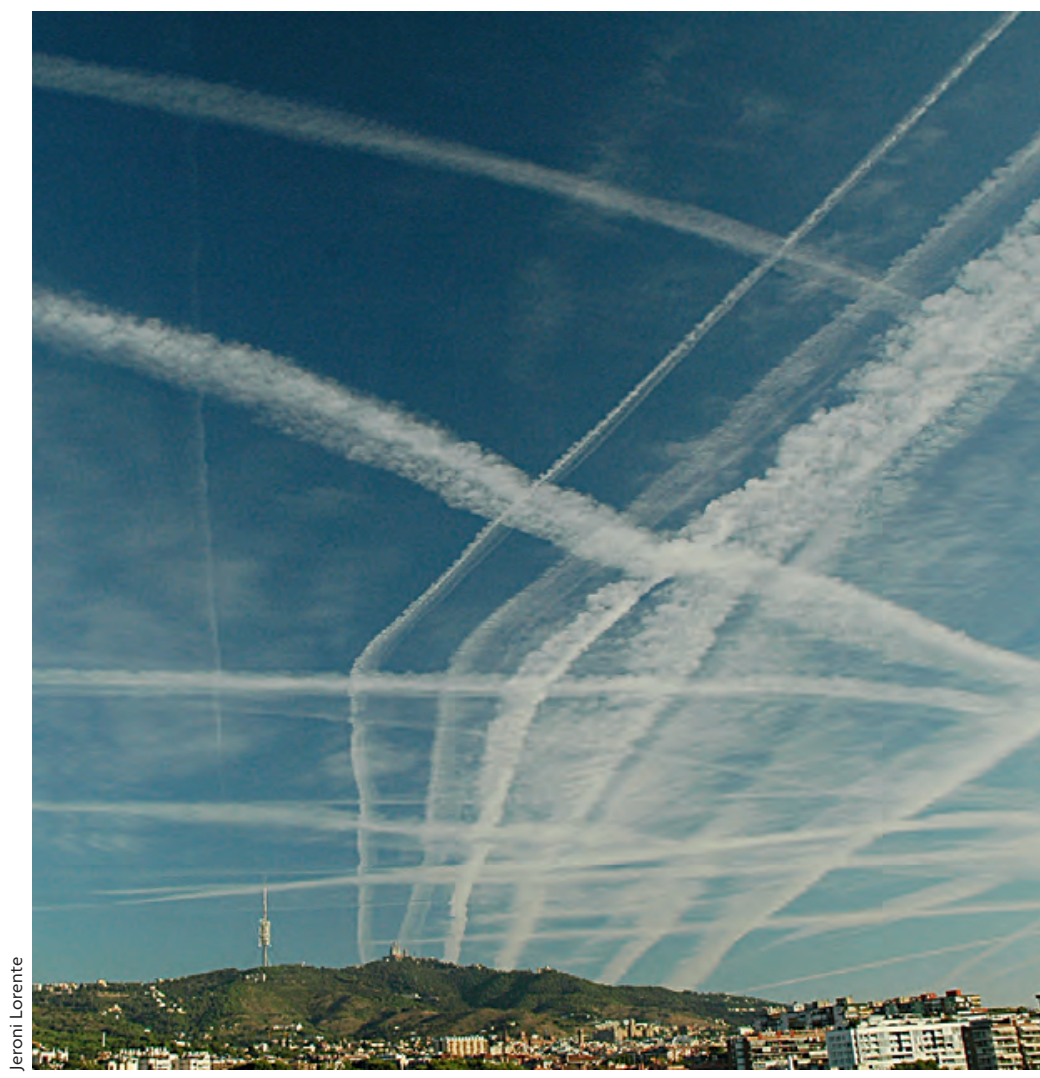

Figure 3. Sky over Barcelona around 11:00 UTC (1 p.m. local time) on 21 September 2011.

\section{Argument 3: Sometimes two aircraft can be seen, only one of which is leaving a trail behind}

Indeed, it is not uncommon to see two aircraft crossing the sky simultaneously, one of them leaving a trail while the other one does not. The scientific explanation for this is that the two aircraft are flying at different atmospheric levels (altitude). Mazon and Pino (2016) proved this with a numerical simulation using the WRF-ARW mesoscale weather research and forecasting model to analyse the atmospheric conditions on a day when almost the entire Catalan coast was covered by contrails. Throughout the morning, the aircraft trails spread instead of disappearing; around noon, they covered the sky. Figure 3 shows a photograph taken in Barcelona at 11:00 UTC (1 p.m. local time) on 21 September 2011, in which the sky is almost entirely covered by contrails.

Figure 4 (left panel) shows the domains covered by the numerical simulation, and the extension of domain 3 (right panel) in which line $\mathrm{AB}$ indicates the direction of the vertical cross sections of the atmosphere used for the temperature and humidity analysis.

Figure 5 shows the vertical cross section along the line $\mathrm{AB}$ in Figure 4 (right panel) of the humidity relative to the ice (in colours) and air temperature (dashed lines) at 11:00 UTC on the day in question. A layer of very humid air is detected around the $10 \mathrm{~km}$ level height, with humidity over $90 \%$. If humid air from the combustion of kerosene is introduced at this level, it could lead to the saturation and deposition of water vapour. Below this layer, humidity decreases quickly (to $70-80 \%$ at 8,500 metres and $50 \%$ at 8,000 metres). The humidity contribution from combustion-derived water crystals required at these levels would be much higher, so saturation would not be as fast.

In addition, it should be noted that the $90 \%$ humidity level present between 9,500 and 10,000 metres coincides with temperatures below $-40^{\circ} \mathrm{C}$, the threshold from which contrails remain without 


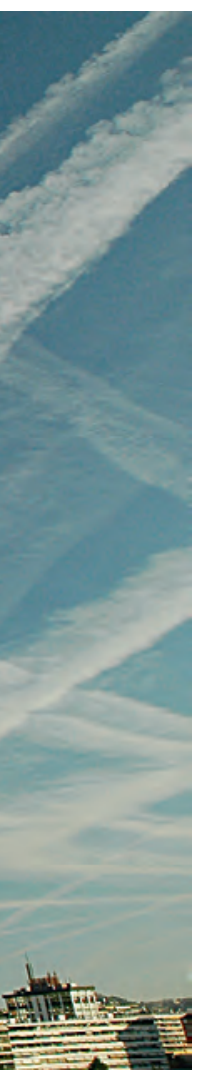

evaporating. At heights below 8,500 metres, the air temperature ascends to between -35 and $-30^{\circ} \mathrm{C}$.

Finally, it is important to point out that from the surface it is not easy to estimate the altitude of a given aircraft or discern whether two are flying at the same level. Therefore, in view of the data in Figure 5, if two aircraft are flying with a vertical separation of 1,000 metres, one will produce a contrail that may remain in the sky for hours while the other one will not.

\section{Argument 4: Interrupted chemtrails often appear: they are not a continuous structure}

The atmospheric conditions in which the ice crystals that form contrails are found can change both in time and space. The numerical simulation performed to describe the atmospheric conditions on 21 September 2011 described above allows us to identify a great variability in the areas of humidity that are more or less favourable to contrail permanence a few hours before and after 11:00 UTC. Figure 6 shows the horizontal distribution of humidity at 9,500 metres (left panel) and the vertical profile of relative humidity and temperature along line AB (right panel) at 02:00 UTC (4 a.m. local time) on 21 September 2011. The simulation shows

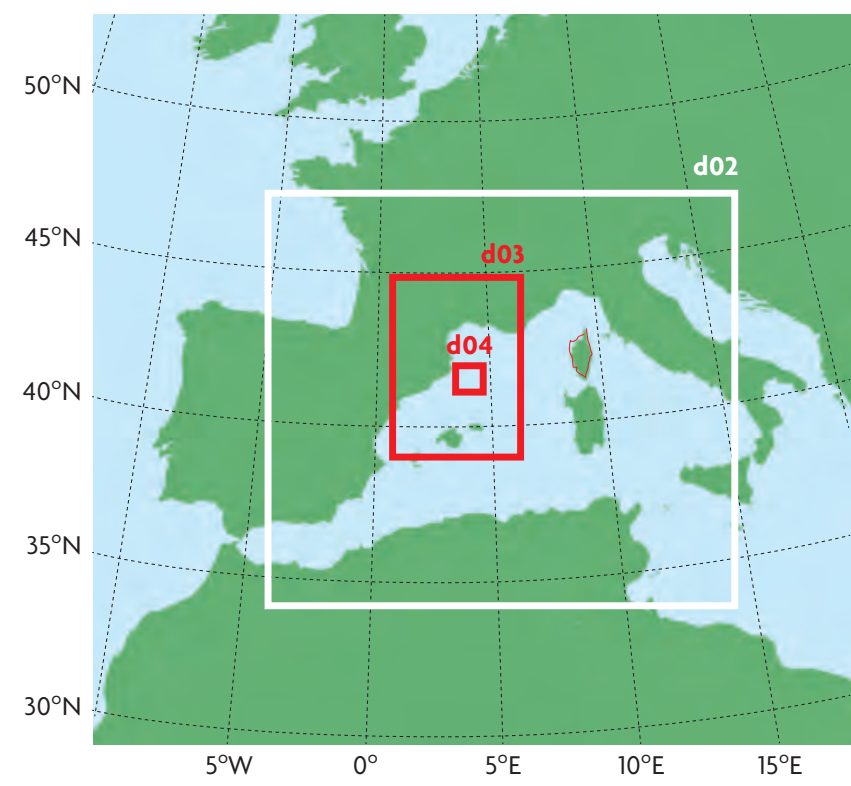

Figure 4. Domains defined for the numerical simulation (left panel), and domain 3 , in which line $A B$ indicates the direction of the vertical cross sections (right panel, in kilometres). unconnected areas with humidity conditions over $80 \%$ (in red), which are thus, conducive to maintaining ice crystals, and areas with values below $70 \%$, that are favourable to the evaporation of ice crystals (in green and blue).

\section{Argument 5: Chemtrails form strange shapes in the sky}

The most common aircraft cruise altitude is around 30,000 feet (about 9,100 metres). Aircraft routes tend to be well defined, and to follow a specific direction and flight level, but they are not accurate. This can lead to contrails looking as if they were parallel or secant lines when conditions favour their appearance.

On the other hand, cruising aircraft usually move at the limit between the troposphere and the stratosphere, where clear-air turbulence (CAT) occurs. This type of turbulence originates from waves in jet streams, persistent air streams located around 10-12 kilometres high, moving eastward at mid-height latitudes. This wave causes

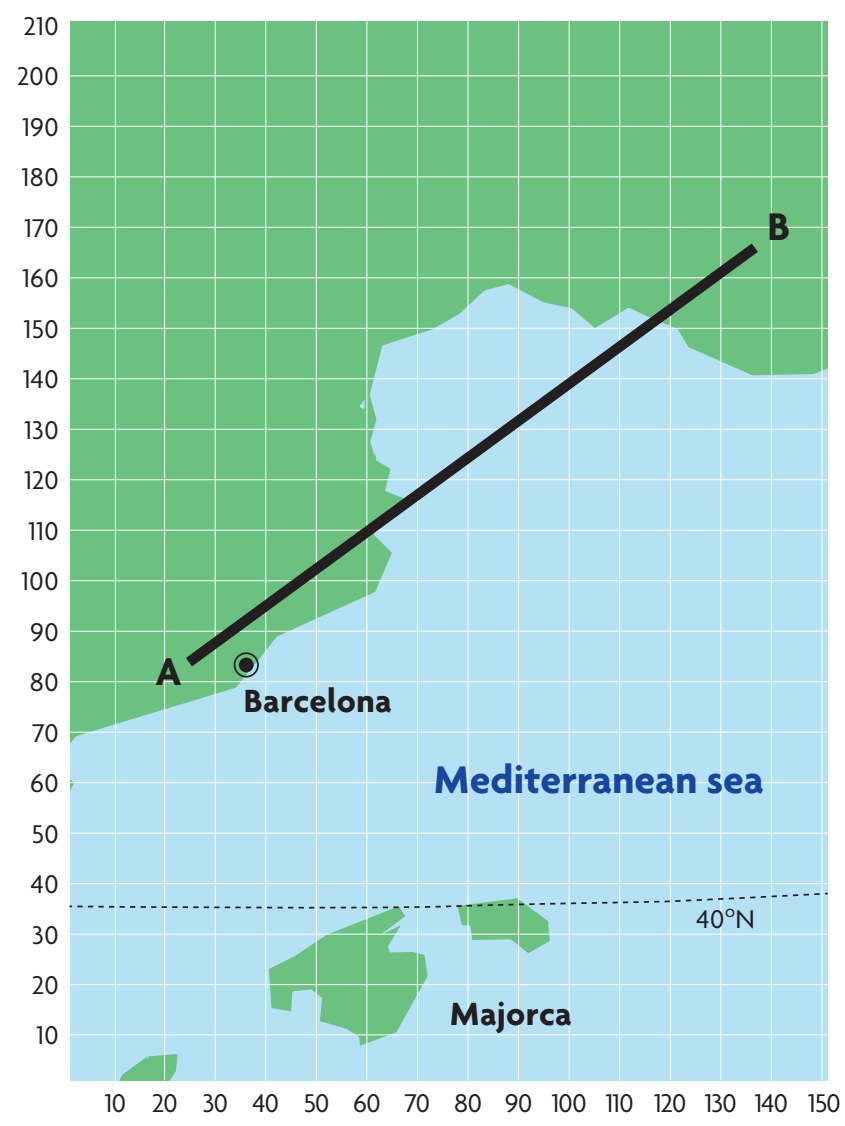




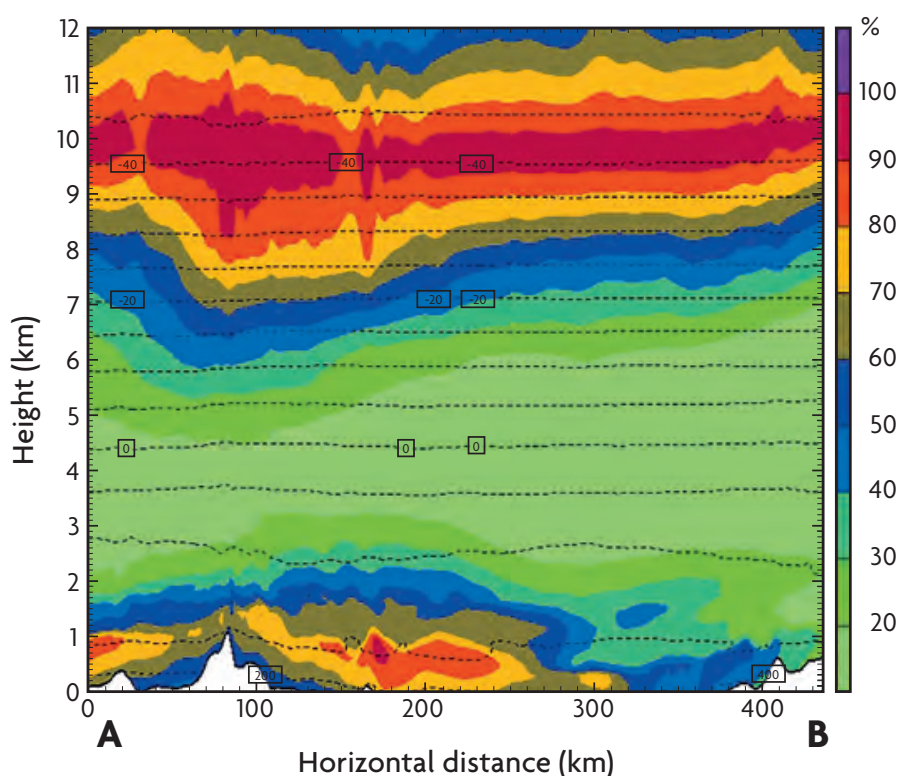

Figure 5. Vertical cross-section along the line AB shown in Figure 4, showing the relative humidity compared to the ice (in colours) and air temperature (dashed lines) at 11:00 UTC (1 p.m. local time) on 21 September 2011. Purple areas represent zones with high relative humidity values, close to $100 \%$, with respect to the ice.

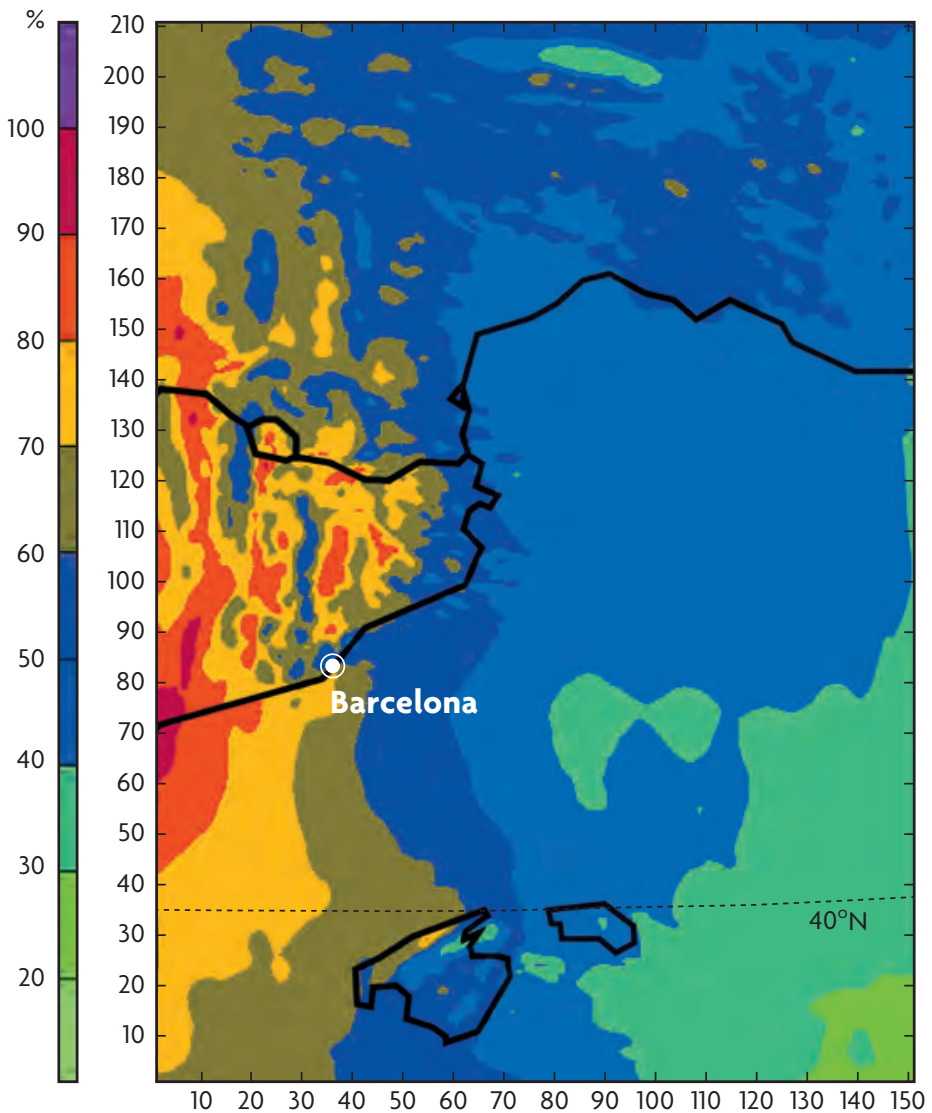

wind shear and the emergence of turbulence, which can explain some of the strange shapes contrails sometimes adopt. In addition to CAT, wind shears produced between the two atmospheric levels can make air move differently between them, causing the air and the ice crystals in the contrails to move irregularly and causing them to take apparently strange shapes.

\section{Argument 6: Toxic and anomalous smells and substances associated with chemtrails are detected at ground level}

Pseudoscience reporters claim to have detected aluminium, barium, and strontium as well as unusual bacteria in the soil, along with the presence of a chemical smell, below the chemtrails they observe in the sky. No scientific evidence supports these assertions, and no scientific publication has provided any evidence for these alleged changes in soil composition. Of the 77 scientists interviewed by Shearer et al. (2016), only one believed that the existence of chemtrails was possible, and his argument was precisely that he had detected strontium in the soil after a contrail event in a remote location in the United States. In addition, any hypothetical chemical emission from high altitudes would not immediately reach the ground and, in any case, these elements would reach the ground as oxides which are sometimes already abundant in the soil. Thus, proof that they originated in the sky would still be required.

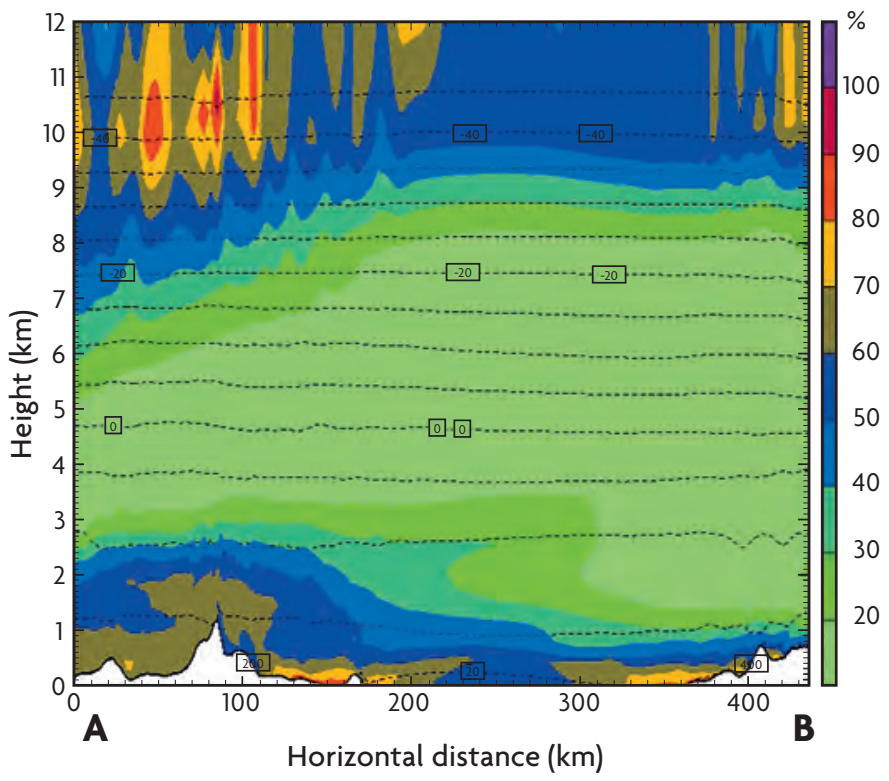

Figure 6. Relative humidity with respect to the ice in domain 3 at 9,500 metres high (left panel) and vertical cross section of the relative humidity with respect to the ice (in colours) and temperature (dashed lines) following line $A B$ shown in Figure 3 at 02:00 UTC (4 a.m. local time) on 21 September 2011 (right panel). 


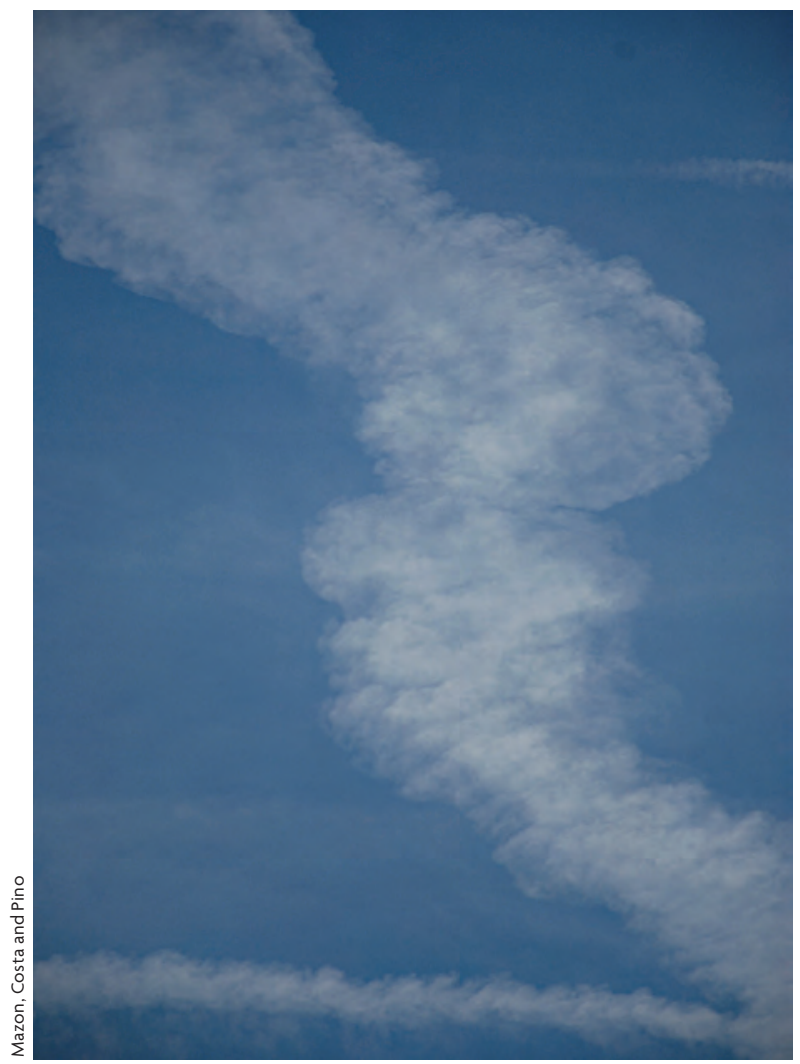

Figure 7. Wavy contrail due to the presence of wind shear at the layer where it formed (Berlin, October 2010).

\section{CONCLUSIONS}

Every major argument made by the advocates of the existence of chemtrails and their associated conspiracy theories can be rebutted with facts about the physical processes involved in the formation of high-level clouds derived from jet aircraft. Despite having an anthropogenic origin, these clouds are made of ice crystals or suffused drops, just like natural clouds.

There is evidence of the formation of condensation trails since the time aircraft started flying in the middle or high layers of the troposphere; i.e., since the beginning of the twentieth century.

The temperature and humidity conditions of the layers in which aircraft fly allow us to predict the formation or absence of contrails, to explain the fact that they only appear at certain levels and their discontinuous appearance. Moreover, the atmospheric dynamics at the altitudes that commercial airliners usually fly at allows us to explain the irregular shapes that contrails sometimes adopt.

Furthermore, there is no evidence for a causeeffect relationship in the detection of chemicals in the ground when contrails occur at high levels. ()

\section{REFERENCES}

Appleman, H. (1953). The formation of exhaust condensation trails by jet aircraft. Bulletin of the American Meteorological Society, 34, 14-20.

Brewer, A. W. (1946). Condensation trails. Weather, 1, 34-40. doi: 10.1002/j.1477-8696.1946.tb00024.x

Ettenreich, R. (1919). Wolkenbildung über einer Feuersbrunst und an Flugzeugabgasen. Meteorologische Zeitschrift, 36, 355-356.

Gierens, K. M. (1996). Numerical simulations of persistent contrails.

Journal of the Atmospheric Sciences, 53(22), 3333-3348. doi: 10.1175/1520-0469(1996)053<3333:NSOPC >2.0.CO;2

Kärcher, B., Peter, T., Biermann, U. M., \& Schumann, U. (1996). The initial composition of jet condensation trails. Journal of the Atmospheric Sciences, 53(21), 3066-3083. doi: 10.1175/1520-0469(1996)053<3066:TICOJC>2.0.CO;2

Mazon, J., \& Pino, D. (2016). A WRF simulation of an episode of contrails covering the entire sky. Atmosphere, 7(7), 95. doi: 10.3390/ atmos7070095

Mazon, J., Costa, M., Pino, D., \& Lorente, J. (2012). Clouds caused by human activities. Weather, 67(11), 302-306. doi: 10.1002/wea.1949

Mercer, A. M., Keith D. W., \& Sharp, J. D. (2011). Public understanding of solar radiation management. Environmental Research Letters, (6)4, 044006. doi: 10.1088/1748-9326/6/4/044006

Minnis, P., Young, D. F., Garber, D. P., Nguyen, L., Smith, W. L., \& Palikonda, R. (1998). Transformation of contrails into cirrus during SUCCES. Geophysical Research Letters, 25(8), 1157-1160. doi: 10.1029/97GL03314

Minnis, P., Ayers, J. K., Palikonda, R., \& Phan, D. (2004). Contrails, cirrus trends, and climate. Journal of Climate, 17, 1672-1685. doi: 10.1175/1520-0442(2004)017<1671:CCTAC>2.0.CO;2

Ryan, A. C., MacKenzie, A. R., Watkins, S., \& Timmis, R. (2011). World War II contrails: A case study of aviation-induced cloudiness. International Journal of Climatology, 32(11), 1745-1753. doi: 10.1002/ joc. 2392

Schröder, F., Kärcher, B., Duroure, C., Ström, J., Petzold, A., Gayet, J. F, ... Borrmann, S. (2000). On the transition of contrails into cirrus clouds. Journal of the Atmospheric Sciences, 57, 464-480. doi: 10.1175/1520-0469(2000)057<0464:OTTOCI>2.0.CO;2

Schumann, U. (1996). On conditions for contrail formation from aircraft exhausts. Meteorologische Zeitschrift, N.F. 5, 4-23.

Schumann, U., \& Wendling, P. (1990). Determination of contrails from satellite data and observational results. In U. Schumann (Ed.), Air Traffic and the Environment-Background, Tendencies and Potential Global Atmospheric Effects (pp. 138-153). Berlin: Springer-Verlag.

Shearer, C., West, M., Caldeira, K., \& Davis, S. J. (2016). Quantifying expert consensus against the existence of a secret, large-scale atmospheric spraying program. Environmental Research Letters, 11(8), 084011. doi: 10.1088/1748-9326/11/12/129501

Varney, B. M. (1921). The Argonne battle cloud. Monthly Weather Review, 49(6), 348-349. doi: 10.1175/1520-0493(1921)49<348b:TABC>2.0.CO;2

Weickmann, L. (1919). Wolkenbildung durch ein Flugzeug. Naturwissenschaften, 7(34), 625. doi: 10.1007/BF01497120

Jordi Mazon Bueso. PhD in Sciences from the Technical University of Catalonia (Spain), undergraduate degree in Physics, and a master's degree in Applied Climatology from the University of Barcelona (Spain). He is currently a professor and researcher in the Department of Physics at the Technical University of Catalonia, tutor for the degree in Environmental Sciences of the National Distance Education University (Spain), and professor at the International Baccalaureate.

Marcel Costa Vila. He has a degree in Biology and works as a high school teacher and at the Department of Experimental and Health Sciences in the Pompeu Fabra University in Barcelona (Spain). He is the author of many science popularisation books in the field of biology and atmospheric events.

David Pino González. PhD in Sciences from the Technical University of Catalonia. He is a lecturer and researcher at the Department of Physics in the Technical University of Catalonia (Spain) and is the principal investigator on several research projects. 